\title{
WORKING PAPER 1903
}

Firm beliefs and long-run demand effects in a labor-constrained model of growth and distribution

Daniele Tavani and Luke Petach

February 2019

POST-KEYNESIAN ECONOMICS SOCIETY 


\title{
Firm Beliefs and Long-run Demand Effects in a
}

\section{Labor-Constrained Model of Growth and Distribution}

\author{
Daniele Tavani*, Luke Petach ${ }^{\dagger}$
}

\begin{abstract}
One of the most debated questions in alternative macroeconomics regards whether demand policies have permanent or merely transitory effects. While Kaleckian ecoomists have argued that demand matters even in the long run, both economists operating within other Keynesian traditions (e.g. Skott. 1989) as well as Classical economists argue that in the long-run output growth is constrained by the so-called natural rate. This paper attempts to bridge the gap by analyzing the role of firm beliefs about the state of the economy in a labor-constrained growth and distribution model based on Kaldor (1956) and Goodwin (1967) but featuring an explicitly dynamic choice of capacity utilization. We show that: (i) the relevance of such beliefs generates an inefficiently low utilization rate and labor share in equilibrium; but (ii) the efficient utilization rate can be implemented through fiscal policy. Under exogenous technical change, (iii) the inefficiency does not affect equilibrium employment and growth, but expansionary fiscal policy has positive level effects on both GDP and the labor share. Conversely, (iv) with an endogenous bias of technical change, fiscal policy will have not just level effects but also long-run effects on labor productivity growth and the employment rate. Finally, (v) the fact that the choice of utilization responds to income shares has a stabilizing effect on growth cycles, even under exogenous technical change, that is analogous to factor substitution.
\end{abstract}

JEL Codes: D25, E12, E22, E25, E62.

Keywords: Beliefs, Capacity Utilization, Coordination Failures, Factor Shares, Fiscal Policy.

\footnotetext{
${ }^{*}$ Corresponding Author. Department of Economics, Colorado State University. 1771 Campus Delivery, Fort Collins, CO 80523-1771. Email:Daniele.Tavani@Colostate.edu

${ }^{\dagger}$ Colorado State University. Email: Luke.Petach@Colostate.edu.
} 


\section{Introduction}

One of the most debated questions in alternative macroeconomic thinking regards whether demand policies have permanent or merely transitory effects. While Kaleckian economists have argued that demand matters even in the long run, both economists operating within other Keynesian traditionssuch as those operating from within the Harrodian tradition (e.g. Skott, 1989, 2010, 2012, 2017)—as well as Classical economists argue that long-run output growth is constrained by the so-called natural rate, and that the long-run rate of utilization of installed capacity, which proxies for effective demand in these frameworks, must necessarily be exogenous. With fully adjusted, exogenous utilization and growth fixed at the natural rate, many of the central results of canonical Kaleckian models appear to be in jeopardy: the paradox of thrift, the paradox of costs, and the relevance of effective demand in the long-run may no longer hold. The latter is especially concerning given the centrality of the principle of effective demand for (post-) Keynesian economics.

All of this points to the question: if one takes the objections of the Harrodian and Classical perspectives seriously, is it necessary to abandon hope for the possibility of a meaningful role for effective demand in the long-run? Our answer is no. While the Classical demarcation limiting the effectiveness of demand policy to the short-run—which has led Duménil and Lévy (1999) to a description of the world as "short-run Keynesian, long-run Classical"-may be analytically useful, it is unlikely to hold true in actually existing capitalist economies. Michl (2017) points out that a key task for alternative economic theories then, is to engage in what theologians call "irenics," or the process of reconciling conflicting doctrines, in order to paint a more realistic picture of the space capitalist economies actually inhabit—a space which undoubtedly combines elements of both the Classical and Keynesian visions (p.74).

Our task in this paper is thus to develop a micro-to-macro, fully Classical model featuring an explicit choice of utilization at the firm level. Our argument is that if firms formulate beliefs about the state of the economy when selecting their own level of capacity utilization, then demand policies can certainly affect the level of economic activity in the long-run-despite growth being fixed at the natural rate. The inclusion of beliefs in our model harkens back to the central role beliefs play in the process of employment determination envisioned by Keynes (1936) in The General Theory: “[T]oday's employment can be correctly described as being governed by today's expectations 
taken in conjunction with today's capital equipment" (p.50). Despite the central role afforded to the process of expectations-formation by Keynes (1936), relatively little effort has been put forth in formalizing these beliefs in (post-) Keynesian models with an explicit microeconomic structure. Borrowing insights from the literature on coordination games (Cooper, 1999), we will show that firm-level beliefs about economic activity can be captured in a simple way by including (expectations about) the aggregate utilization rate in the economy as a signal for the current level of effective demand. To gain intuition, consider the following scenario. Suppose an individual firm, operating at its desired utilization, expects other firms to increase production because the economy is picking up steam. If such beliefs did not have an effect on the firm's choice, then it must be true that the firm has already maximized its profits and has no incentive to deviate from the corresponding utilization choice. But this cannot be the case, because the firm will in fact increase its profits by simply utilizing more its capacity in light of its beliefs about the economy. Thus, it must be that beliefs enter the choice of utilization at the firm level.

Following Tavani and Petach (2018), we operationalize this assumption via the Keynesian notion of the user cost of capital - the opportunity cost incurred by firms whenever they choose to undertake production. Importantly, the concept of user cost as outlined by Keynes (1936) is outwardlooking: "[I]t is the expected sacrifice of future benefit involved in present use which determines the amount of user cost, and it is the marginal amount of this sacrifice which... determines his (sic) scale of production" (p.70). In other words, the user-cost of capital does not merely depend on the firm's current own-rate of utilization. On the one hand, our rendition of the user cost has an individual component and it is increasing and convex in the firm's own utilization rate (Greenwood et al. 1988). On the other hand, the user cost function has an outward-looking component, captured by its dependence on the average rate of utilization-which we take as an index of the individual firm's beliefs about the behavior of the aggregate economy - in order to capture the individual firm's incentives to adjust its production given changes in expectations. Accordingly, we propose a user cost specification where the marginal user cost is declining in the average rate of utilization in the economy. Under empirically-sound restrictions, this way of formalizing the user cost delivers strategic complementarities among firms: the desired rate of utilization at the firm level increases in aggregate utilization - that is, is endogenous to demand. This feature will produce an equilibrium utilization rate, and therefore an equilibrium level of economic activity, that is inefficiently low. 
The result can then be used in order to draw policy implications. With exogenous technical change - the most common specification of technological progress in Harrodian models- the economy's growth rate is fixed and equal to the natural rate $n$. Accordingly, there are no growth effects of demand policies. However, underutilization implies that spending policies have positive level effects, both on output per worker and the share of labor. The latter will increase in response to spending policies that boost economic activity.

In addition to analyzing the effects of demand policies on an economy's balanced growth path, we also consider the implications of incorporating the user cost of capital and modeling explicitly the strategic choice of capacity utilization for the Goodwin (1967) growth cycle, whose steady state is identical to Kaldor (1956) but whose focus is on the endless distributive cycle between the employment rate and the labor share. The literature has identified four main channels through which the perpetual cycle can be resolved in the long run: (i) capital/labor substitution along a NeoClassical production function (van der Ploeg, 1985); (ii) an endogenous labor-augmenting bias of technical change (Shah and Desai, 1981; Foley, 2003; Julius, 2005); (iii) endogenous laboraugmenting innovation financed out of profits (Tavani and Zamparelli, 2015), and (iv) differential tax rates on capital versus labor incomes (Tavani and Zamparelli, 2018). In all of these cases, the symmetry in the bargaining positions between capital and labor, which is responsible for the endless Goodwin growth cycle (Shah and Desai, 1981), is broken in favor of the former. We show in this paper that the choice of utilization implied by our model acts in the same way, namely turning the resulting steady state from the Goodwin center to a stable focus. Essentially, the possibility of varying the rate of utilization is analogous to changing the technique of production in response to factor shares, which is at the heart of the three stabilizing channels discussed in the literature. Thus, the conclusions of this analysis are that demand matters even in the long run, both for the level of economic activity and the labor share.

Finally, we also analyze a version of the model featuring an endogenous direction of technical change in response to income shares (Kennedy, 1964; Drandakis and Phelps, 1965). In this case the growth rate of labor productivity responds directly to the share of labor, expansionary fiscal policy that fosters utilization will increase the labor share thus determining a long-run growth effect—and not only a level effect. This version of the model therefore exhibits a type of hysteresis, wherein short-run level-effects translate meaningfully into changes in the long-run growth rate via their im- 
pact on the distribution of income. Thus, our paper contributes to the literature examining hysteresis in Classical and Keynesian growth models (Setterfield, 2018; Michl and Oliver, 2019), and offers one explanation for why temporary demand shocks have permanent level effects under exogenous growth, or permanent growth effects under endogenous labor-augmenting technical change.

\section{Basic Elements of the Model}

Consider a representative, competitive capitalist firm in a closed economy. For now, assume away the government for simplicity. The firm's production possibilities are summarized by the Leontief technology $Y=\min \{u K, A L\}$ where: $Y$ is the firm's output, homogeneous with capital stock $K$ so that we can normalize its price to one; $u$ denotes the rate of capacity utilization; $L$ stands for labor; $A$ is the current stock of labor-augmenting technologies, assumed to grow at the constant rate $g_{A}>$ 0 in the benchmark model, so that the analysis is as close as possible to baseline Harrodian models such as Skott (1989); and the long-run output/capital ratio $B$ is normalized to one for simplicity. Time is continuous. Maximizing profits requires to set $u K=A L$, which solves for labor demand $L=u K / A$. If the firm pays the same real wage $w$ to each worker, the share of wages in output will be equal to the unit labor cost: $\omega \equiv w / A$. Further, let the labor force $N \geq L$ grow at the constant rate $n>0$. Thus, the employment rate in the economy $e$ will be equal to $L / N=u K /(A N)$.

Our main hypothesis is that operating capital equipment entails a user cost $\lambda$, which would not be incurred if machinery remained idle (Keynes, 1936). To capture the user cost, first, we assume that the user cost increases more than proportionally with the firm's own utilization rate $u$ : denoting partial derivatives by subscripts, $\lambda_{u}>0, \lambda_{u u}>0$. Greenwood et al. (1988) have noted that this specification formalizes the Keynesian effects played by the 'marginal efficiency of investment' and the Keynesian notion of user cost for the individual firm. Second, we capture the strategic nature of the choice of utilization by postulating that the user cost also responds to the firm's beliefs about the utilization chosen by other firms as captured by $\tilde{u}$, the average utilization rate. We assume that $\tilde{u}$ has a negative impact on the marginal user cost: $\lambda_{u \tilde{u}}<0$. This assumption implies that the marginal benefit of increasing own utilization increases in the firm's beliefs about aggregate utilization, and is required to generate a strategic complementarity, which is central in our contribution. Tavani and Petach (2018) have offered strong and robust empirical support for this assumption using a panel of 
state-by-sector data for the United States. To sharpen our conclusions, we specify a log-linear user cost function as in Tavani and Petach (2018):

$$
\lambda(u ; \tilde{u})=\beta u^{\frac{1}{\beta}} \tilde{u}^{-\frac{\gamma}{\beta}}, \beta \in(0,1), \gamma \in[0,1-\beta)
$$

The size of the parameter $\gamma$ determines the extent to which beliefs about other firms' behavior are relevant for the firm choice. The special case $\gamma=0$ corresponds to the isolated firms case where the choices made by other firms are irrelevant, while $\gamma \neq 0$ implies a strategic environment in which beliefs matter. Further, under $0<\gamma+\beta<1$, the choice of utilization generates a (weak) strategic complementarity, which will result in a unique long-run equilibrium in the model. The estimates in Tavani and Petach (2018) strongly support the above parametric restriction that $0<\gamma<1-\beta$.

In line with the basic Classical and Post Keynesian literature, we assume that only profit-earning (capitalist) households save in order to accumulate capital stock. However, while in most of the literature capitalists save a constant fraction of their profit incomes at all times, we follow Foley, Michl and Tavani (2019) in assuming that capitalist households are forward-looking in their consumption, accumulation, and utilization decisions. This assumption is made here in order to rule out any potential 'inefficiency' result implied by a limited planning horizon, or by 'rule of thumb' behavior such as saving the same fraction of income at all times $1^{1}$ Here, the capitalist household discounts the future at a constant rate $\rho>0$, derives instantaneous logarithmic utility from its per-period consumption flow, denoted by $c(t)$, and has perfect foresight on the entire planning horizon $t \in[s, \infty)$. Finally, assume that there is no independent investment demand function, so that capitalist savings are immediately invested at all times. The accumulation constraint, omitting the time-dependence for notational simplicity, is:

$$
\dot{K}=(1-\omega) u K-c-\lambda(u ; \tilde{u}) K
$$

Note that increasing the own rate of utilization raises the capitalist's revenues $(1-\omega) u K$, but also increases the user cost of capital $\lambda(u ; \tilde{u})$ given average utilization. As shown in Appendix A the solution to a simple control problem delivers the firm-level choice of capacity utilization as a

\footnotetext{
${ }^{1}$ Similar reasoning applies to the assumption of competitive firms: the results of the model do not depend on slow price adjustments, as Skott (2017) has argued to be the case in neo-Kaleckian growth models.
} 
decreasing function of the labor share while increasing in average utilization as per equation (3) below. The firm-level choice of utilization is equivalent to a best-response function in the gametheoretic sense, or a reaction function in Cournot-style models.

$$
u(\omega ; \tilde{u})=(1-\omega)^{\frac{\beta}{1-\beta}} \tilde{u}^{\frac{\gamma}{1-\beta}}
$$

Figure 1 displays the behavior of the best-response function in relation to the aggregate utilization rate. The intuition for the inverse dependence on the labor share is that an increase in the latter reduces revenues everything else equal: the firm can then cut back on its utilization in order to reduce the user cost of capital. On the other hand, an increase in aggregate utilization reduces the own marginal user cost of capital everything else equal, thus rising the marginal profits that can be made by utilizing more a firm's own installed capacity: the firm can increase utilization up to the point where the marginal benefit of doing so-given by $(1-\omega) K$-is equal to the marginal user cost $\lambda_{u}(u ; \tilde{u}) K$ for a given average utilization rate. Finally, given that the firm's beliefs about aggregate utilization represent expectations about the overall economic activity in the economy, the dependence on average utilization can be thought of as capturing the endogeneity of the firm's desired rate of utilization to demand. Appendix $\mathrm{A}$ also shows that the growth rate of consumption for the typical capitalist household—which describes the household-level saving rule—satisfies:

$$
g_{c} \equiv \frac{\dot{c}}{c}=(1-\omega)^{\frac{1}{1-\beta}} \tilde{u}^{\frac{\gamma}{1-\beta}}-\rho
$$

Figure 1: Equilibrium vs. efficient utilization rates.

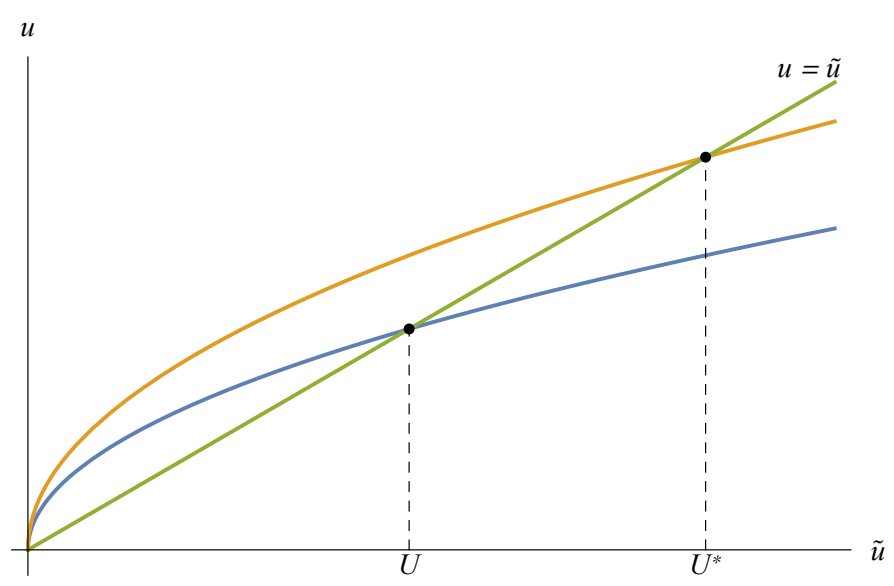




\section{Equilibrium Utilization and Accumulation}

An equilibrium growth path is a sequence of quantities $\{c(t), u(t), \tilde{u}(t), k(t)\}_{t \in[s, \infty)}$ that solve the capitalist's control problem given the path for the labor share $\{\omega(t)\}_{t \in[s, \infty)}$ and such that $u(t)=$ $\tilde{u}(t)$ for all $t$. The latter requirement requires firms to best-respond to other firms' choices, similarly to the notion of a Nash equilibrium. Omitting the time notation for simplicity, the equilibrium rate of utilization is easily found as

$$
u(\omega)=(1-\omega)^{\frac{\beta}{1-\beta-\gamma}}
$$

and is inversely related to the labor share, since $1-\beta-\gamma>0$ by assumption. The intuition is simple: a higher wage share lowers the firm's profits and thus the resources available for accumulation. But the firm can offset the higher wage costs by utilizing less its plants, thus reducing the user cost.

We can then obtain the equilibrium growth rate by using the condition $u=\tilde{u}$ and imposing balanced growth so that consumption and capital stock grow at the same rate: $g_{c}=g_{K}=g$. We have:

$$
g=(1-\beta)(1-\omega)^{\frac{1-\gamma}{1-\beta-\gamma}}-\rho
$$

\section{The Dynamical System}

First, consider the economy's share of labor $\omega=w / A$. Its growth rate will be given by the difference between the growth rate of the real wage and the growth rate of labor productivity. Following Goodwin (1967), assume that real wages obey a version of the Phillips curve $\dot{w} / w=f(e)$ such that $f_{e}>0, f_{e e}>0$. As in Tavani and Zamparelli (2015), we impose $f(e)=\eta e^{1 / \delta}, \eta>0, \delta \in(0,1)$. Hence, the labor share evolves according to:

$$
\frac{\dot{\omega}}{\omega}=f(e)-g_{A}
$$

Next, consider the employment rate $e=u K /(A N)$. Logarithmic differentiation gives:

$$
\frac{\dot{e}}{e}=g_{K}+g_{u}-\left(g_{A}+n\right)
$$


Differentiating (5), we obtain the growth rate of utilization as:

$$
\frac{\dot{u}}{u} \equiv g_{u}=-\frac{\beta}{1-\beta-\gamma}\left(\frac{\omega}{1-\omega}\right) \frac{\dot{\omega}}{\omega}
$$

so that, using the real-wage Phillips curve (7) and the accumulation rate from (6), we find:

$$
\dot{e}=\left\{(1-\beta)(1-\omega)^{\frac{1-\gamma}{1-\beta-\gamma}}-\frac{\beta}{1-\beta-\gamma}\left(\frac{\omega}{1-\omega}\right)\left[f(e)-g_{A}\right]-\left(\rho+g_{A}+n\right)\right\} e
$$

\subsection{Steady State}

A steady state is a pair $\left(\omega_{s s}, e_{s s}\right)$ so that $\dot{\omega}=\dot{e}=0$. Notice that the steady state value of utilization is uniquely pinned down by the steady state labor share, given the equilibrium condition $u=\tilde{u}$ above. The steady state value of the employment rate is found by setting $\dot{\omega}=0$ in (7):

$$
e_{s s}=\left(\frac{g_{A}}{\eta}\right)^{\delta}
$$

Note that steady state employment is fully exogenous because of the exogenous nature of technological change in the model. On the other hand, the steady state value for the labor share can be solved for in closed form once noting that $f\left(e_{s s}\right)=g_{A}$ in setting the right-hand side of equation 9 equal to zero. By so doing, we find:

$$
1-\omega_{s s}=\left(\frac{\rho+n+g_{A}}{1-\beta}\right)^{\frac{1-\beta-\gamma}{1-\gamma}}
$$

which, using [5], yields the steady state utilization rate:

$$
u_{s s}=\left(\frac{\rho+n+g_{A}}{1-\beta}\right)^{\frac{\beta}{1-\gamma}}
$$

Notice that the paradox of thrift holds in this model. A higher value of the discount rate $\rho$ reduces capitalists' saving, but increase utilization and therefore the long-run level of economic activity. 


\subsection{Stability Analysis}

Appendix C shows that, unlike the original Goodwin (1967) long-run, the steady state of this model is stable. Thus, the explicit choice of capacity utilization is an alternative way of breaking the symmetric bargaining positions between capital and labor, resolving the distributive conflict in the long run. Figure 3 shows the $\dot{\omega}=0$ nullcline, which is vertical corresponding to the steady state employment rate $e_{s s}$ and is the same at both the equilibrium and the efficient solution; and plots the equilibrium $\dot{e}=0$ in red. Notice however that convergence to the steady state is not monotonic: the employment rate, which is the forward-looking variable in this model, overshoots before converging to its long-run value. In this respect, explicit demand shocks (see below) will determine some shortrun cyclical behavior of the system before convergence to a new steady state is achieved.

Figure 2: Equilibrium vs. efficient trajectories for the employment rate and the labor share.

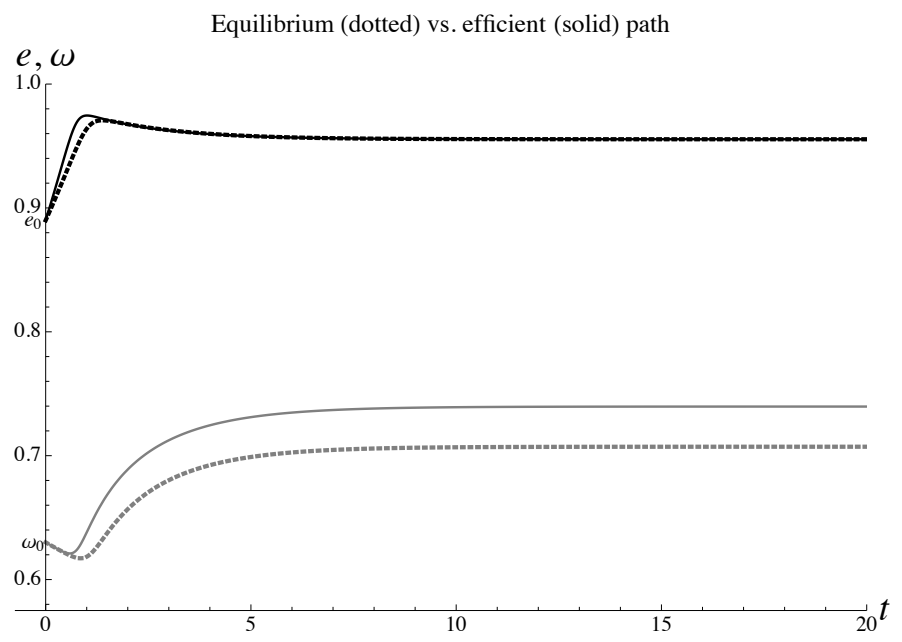

\section{Welfare and Policy}

An interesting feature of this model is that so long as a strategic context between firms is presentthat is so long as $0<\gamma<1-\beta$-it will generally operate with excess capacity in equilibrium, while at the same time accumulating capital stock. To see this, suppose that a benevolent planner solves the accumulation problem under the additional constraint that $u=\tilde{u}$ at all times. Appendix B proves the following result. 
Figure 3: Phase Diagram: equilibrium nullclines (red) and efficient $\dot{e}=0$ nullcline (blue), and dynamic trajectories converging to the equilibrium (dotted gray) as opposed to the efficient (solid black) steady state.

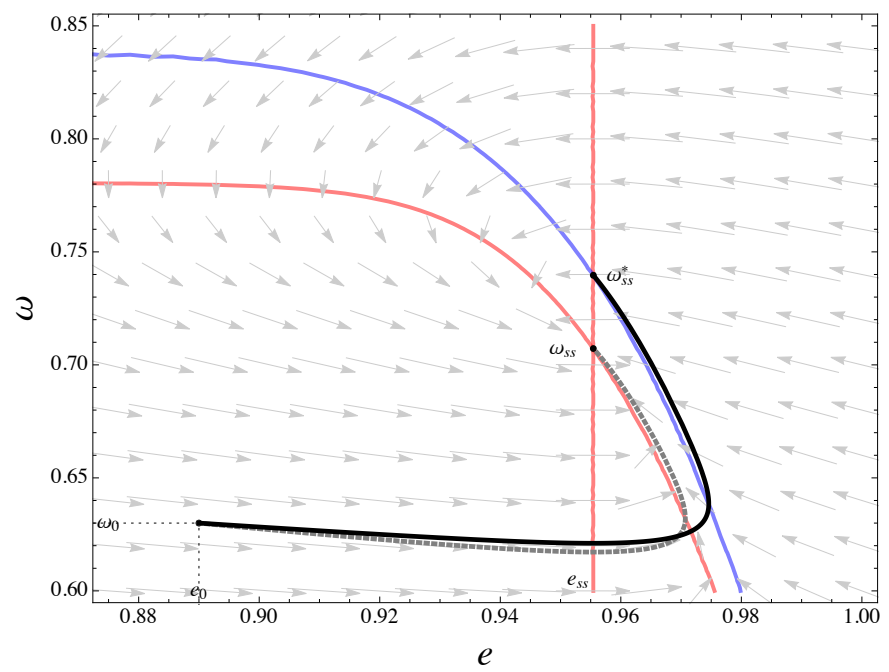

Proposition 1 Let $\gamma \in(0,1-\beta)$. Then, the efficient choice of utilization is:

$$
u^{*}(\omega)=\left(\frac{1-\omega}{1-\gamma}\right)^{\frac{\beta}{1-\beta-\gamma}}
$$

and is strictly greater than its decentralized counterpart (5).

Notice that the parameter $\gamma$ generates a multiplier effect: the larger the extent to which firm beliefs matter, the higher the socially-coordinated utilization rate relative to the equilibrium rate. Absent a role for beliefs, $\gamma=0$ : the equilibrium rate and the socially-coordinated rate coincide. This result is important for two reasons: first, as long as firms operate within a strategic context, they will find it profit-maximizing to keep accumulating capital stock even though their capacity is not fully utilized. Second, the result shows that the individual component of the user cost function is not sufficient to generate underutilization: the presence of a strategic environment where firms' decisions are affected by other firms' choices is necessary for the economy to operate below full capacity in equilibrium. Figure 1 shows the equilibrium as opposed to the efficient utilization rate in this model. Using [11], we can then solve for the efficient accumulation rate as

$$
g^{*}=\left(\frac{1-\omega}{1-\gamma}\right)^{\frac{1-\gamma}{1-\beta-\gamma}}(1-\beta-\gamma)-\rho
$$


which can then be used in order to track the evolution of employment along the efficient growth path. The law of motion for the labor share does not change: therefore, the efficient steady state value for the employment rate is still given by equation $(E)$ above. Instead, the evolution of employment over time modifies to:

$$
\frac{\dot{e}}{e}=(1-\beta-\gamma)\left(\frac{1-\omega}{1-\gamma}\right)^{\frac{1-\gamma}{1-\beta-\gamma}}-\frac{\beta}{1-\beta-\gamma}\left(\frac{\omega}{1-\omega}\right)\left[f(e)-g_{A}\right]-\left(\rho+g_{A}+n\right)
$$

Proceeding as before, then, we find the steady state labor share at the efficient growth path as the solution to:

$$
1-\omega_{s s}^{*}=(1-\gamma)\left(\frac{\rho+g_{A}+n}{1-\beta-\gamma}\right)^{\frac{1-\beta-\gamma}{1-\gamma}}
$$

The Appendix, then, proves the following result.

Proposition 2 Let $1-\beta>\gamma>0$. Then, $\omega_{s s}^{*}>\omega_{s s}$.

Tavani and Petach (2018) have estimated equation (3) through a series of empirical models using state-by-sector US data with the aim of assessing the extent of strategic complementarities. Those results provide strong evidence regarding the empirical bite of our argument. The point estimates for the main parameters of interest, $\gamma$ and $\beta$, are highly significant and robust to different model specifications, and fully in line with the theoretical restrictions needed for Proposition 2 to hold. Thus, the analysis provides strong reasons to believe that demand policies can be used in order to improve the workers' distributional position in the economy. We carry a simple exercise to this aim in the next Section.

\subsection{Policy}

Let us introduce a government authority that subsidizes the user cost at a rate $s$, and-for simplicitytaxes capitalist income lump-sum by an amount $\tau$ while running a balanced budget: $\tau=s \lambda(\cdot) K 2^{2}$ The capitalist households' budget constraint modifies as follows:

$$
\dot{K}=(1-\omega) u K-\tau-c-\lambda(u, \tilde{u}) K(1-s)
$$

\footnotetext{
${ }^{2}$ Setting $\tau=0$ amount to impose a deficit-financed user cost subsidy.
} 
Solving the corresponding optimal control problem, we have the following result, proven in the Appendix.

Proposition 3 The subsidy that decentralizes the socially-coordinated utilization rate is equal to $\gamma$, the extent of strategic complementarities. Further, the aggregate response to an increase in the user cost subsidy is always greater than the individual firm's response. The resulting 'fiscal multiplier' is equal to $\frac{1}{1-\frac{\gamma}{1-\beta}}$.

\section{Endogenous Direction of Technical Change}

Following Julius (2005), suppose we extend the model so that firms have access to a menu of technological improvements that can in principle increase either the growth rate of labor productivity $g_{A}$ or $g_{B}$, the growth rate of the long-run output-capital ratio $B$ which is not always constant as a result. Let the trade-off between such technological improvements be represented by a strictly decreasing, strictly concave invention possibility frontier (IPF) such that $g_{B}=h\left(g_{A}\right), h^{\prime}<0, h^{\prime \prime}<0$. Let firms choose a profile of technical change so as to maximize the rate of unit cost reduction, given by $\omega g_{A}+(1-\omega) g_{B}$, under the IPF constraint (Kennedy, 1964; Drandakis and Phelps. 1965, Funk, 2002). Such choice gives the direction of technical change as a function of factor shares as follows: $-h^{\prime}\left(g_{A}\right)=\omega /(1-\omega)$. If, for concreteness, we specify the IPF as follows: $g_{B}=z-\theta g_{A}^{1 / \theta}, \theta \in(0,1)$, the growth rate of labor productivity satisfies:

$$
g_{A}(\omega)=\left(\frac{\omega}{1-\omega}\right)^{\frac{\theta}{1-\theta}}
$$

and it is increasing in the labor share. Plugging this expression in the evolution of the labor share and solving for a steady state such that $\dot{\omega}=0$, we find the following nullcline describing a long-run direct relationship between the employment rate and the labor share:

$$
e_{s s}=\left[\frac{1}{\eta}\left(\frac{\omega_{s s}}{1-\omega_{s s}}\right)^{\frac{\theta}{1-\theta}}\right]^{\delta}
$$

While the solution for the steady state labor share in this version of the model does not have a closed form, it is not hard to show that its equilibrium value will be lower than the efficient value 
since the utilization rate in equilibrium will also be lower than its efficient counterpart. Thus, using fiscal policy to expand utilization up to its efficient rate will increase the labor share as in the benchmark model with exogenous technical change; in addition, however, it will have positive longrun effects on the employment rate and the rate of labor productivity growth via the endogenous bias of technical change.

\section{Conclusion}

In this paper we have offered one potential resolution to what Michl 2017) calls the "discord in the marriage of Classical and Keynesian economics that defines modern heterodox macroeconomics" (p.77). Namely, the discord caused by conflicting claims about the relationship of effective demand to long-run growth. Our solution relies on the introduction of beliefs into the firm's choice of utilization in an otherwise Classical long-run model of growth and distribution. Firms' beliefs are modeled via a user cost function that exhibits a declining marginal user cost in the economy-wide rate of utilization. Under reasonable and empirically-supported restrictions on parameter values, we showed that this specification is sufficient to generate a desired utilization rate at the firm level that increases in aggregate utilization. As a result, we are able to carve out a role for demand policy in our model. Even though growth is fixed at the natural rate, spending policies will always have level effects on output because equilibrium utilization is below the efficient level. We then provided extensions of the model to capture a Goodwin (1967) growth cycle on the one hand, and an endogenous direction of technical change on the other. With the former, the choice of utilization resolves distributive conflict in favor of the capitalist class, altering the steady-state of the Goodwin model into a stable focus. However, the model exhibits overshooting of the employment equilibrium, consistent with Keynes (1936). For the latter, the dependence of labor productivity growth on the labor share introduces the possibility of hysteresis, as demand shocks will subsequently impact the rate of growth via their impact on the labor share.

As a final observation, the focus of this paper is on the effectiveness of fiscal policy in laborconstrained economies. Our analysis points to the relevance of coordination failures in devising a role for spending policies that will increase economic activity and the labor share, despite equilibrium utilization being profit-led in the usual Post-Keynesian jargon. Even though our model 
is essentially supply-side, we showed that the paradox of thrift holds, and that spending policies will generally have multiplier effects. Our conclusions will only be reinforced in an analysis that includes a demand-driven determination of economic activity.

\section{A The Capitalists' Optimization Problem}

Suppose that the representative capitalist household has logarithmic preferences over consumption streams, and discounts the future at a constant rate $\rho>0$. Then, the household solves:

$$
\begin{array}{lll}
\text { Given } \tilde{u}, \text { Choose }\{c(t), u(t)\}_{t \in[s, \infty)} \text { to maximize } & \int_{s}^{\infty} \exp \{-\rho(t-s)\} \ln c(t) d t \\
& \text { subject to } \quad & \dot{K}=(1-\omega) u(t) K(t)-c(t)-\lambda[u(t) ; \tilde{u}] K(t) \\
& K(s) \equiv K_{s}>0, \text { given } \\
& \lim _{t \rightarrow \infty} e^{-\rho(t-s)} K(t) \geq 0
\end{array}
$$

Observe first that the problem stated in 17 involves a strictly concave objective function to be maximized over a convex set. Thus, the standard first-order conditions on the associated currentvalue Hamiltonian

$$
\mathcal{H}=\ln c+\mu[u(1-\omega) K-c-\lambda(u ; \tilde{u}) K]
$$

will be necessary and sufficient for an optimal control. They are:

$$
\begin{aligned}
c^{-1} & =\mu \\
1-\omega & =\lambda_{u}(u, \tilde{u}) \\
\rho \mu-\dot{\mu} & =\mu[(1-\omega) u-\lambda(u ; \tilde{u})] \\
\lim _{t \rightarrow \infty} e^{-\rho t} \mu(t) k(t) & =0
\end{aligned}
$$

Solving (19) for the rate of utilization under the specific functional form (1) gives (3). To obtain the Euler equation for consumption, differentiate (18) with respect to time and use (18) and (20) to get:

$$
g_{c} \equiv \frac{\dot{c}}{c}=(1-\omega) u(\omega ; \tilde{u})-\{\lambda[u(\omega ; \tilde{u})]+\rho\}
$$


Using both (3) and (1) while imposing a balanced growth path where consumption and capital stock grow at the same rate gives (4).

\section{B The Efficient Solution}

A benevolent social planner (or 'world capitalist' as in Foley, Michl and Tavani (2019), Chapter 18) solves the accumulation problem under the additional constraint that $u=\tilde{u}$ at all times. Accordingly, the accumulation problem (17) is solved under the modified accumulation constraint

$$
\dot{K}=u(1-\omega) K-c-\beta u^{\frac{1-\gamma}{\beta}} K
$$

The first-order condition on consumption is the same as (18) above. On the other hand, the choice of utilization and the costate equation satisfy the first-order conditions which, once again, are necessary and sufficient for an optimal control:

$$
\begin{aligned}
1-\omega & =(1-\gamma) u^{\frac{1-\beta-\gamma}{\beta}} \\
\rho-\frac{\dot{\mu}}{\mu} & =u(1-\omega)-\beta u^{\frac{1-\gamma}{\beta}}
\end{aligned}
$$

Solving equation (23) for utilization gives (11). To obtain the efficient accumulation rate (12), simply impose a balanced growth path.

\section{Stability Analysis}

\section{C.1 Equilibrium Path}

The Jacobian Matrix evaluated at a steady state has the following sign structure

$$
J\left(e_{s s}, \omega_{s s}\right)=\left[\begin{array}{cc}
-\frac{\beta}{1-\beta-\gamma} \frac{\omega_{s s}}{1-\omega_{s s}} f^{\prime}\left(e_{s s}\right) e_{s s} & -\frac{(1-\beta)(1-\gamma)}{1-\beta-\gamma}\left(1-\omega_{s s}\right)^{\frac{\beta}{1-\beta-\gamma}} e_{s s} \\
(-) & (-) \\
f^{\prime}\left(e_{s s}\right) \omega_{s s} & 0 \\
(+) & (0)
\end{array}\right]
$$


Thus, it has a negative trace and a positive determinant. It follows that its eigenvalues are of the same sign and sum to a negative number, which can only occur if they both have uniformly negative real parts. We conclude that the steady state is stable.

\section{C.2 Efficient Path}

The Jacobian Matrix evaluated at the efficient steady state is:

$$
J\left(e_{s s}, \omega_{s s}^{*}\right)=\left[\begin{array}{cc}
-\frac{\beta}{1-\beta-\gamma} \frac{\omega_{s s}^{*}}{1-\omega_{s s}^{*}} f^{\prime}\left(e_{s s}\right) e_{s s} & -\left(\frac{1-\omega_{s s}^{*}}{1-\gamma}\right)^{\frac{\beta}{1-\beta-\gamma}} e_{s s} \\
(-) & (-) \\
f^{\prime}\left(e_{s s}\right) \omega_{s s}^{*} & 0 \\
(+) & (0)
\end{array}\right]
$$

again, with negative trace and positive determinant, so that the efficient steady state is stable, too.

\section{Proofs}

- Proposition 1. Consider that that, using (5) and (11),

$$
\frac{u^{*}}{u}=\left(\frac{1}{1-\gamma}\right)^{\frac{\beta}{1-\beta-\gamma}}>1
$$

since $0<\gamma<1-\beta$ by assumption.

- Proposition 2. Showing that $\omega^{*}>\omega$ is tantamount to showing that $\ln (1-\omega)-\ln \left(1-\omega^{*}\right)>0$.

We have that

$$
\begin{aligned}
D_{\omega} & \equiv \ln (1-\omega)-\ln \left(1-\omega^{*}\right) \\
& =\frac{1-\beta-\gamma}{1-\gamma}[\ln (1-\beta-\gamma)-\ln (1-\beta)]-\ln (1-\gamma)
\end{aligned}
$$

and

$$
\frac{\partial D_{\omega}}{\partial \gamma}=-\frac{\beta}{(1-\gamma)^{2}}[\ln (1-\beta-\gamma)-\ln (1-\beta)]
$$

Hence, the difference $D_{\omega}$ increases in $\gamma$ provided that the term in brackets is negative. This is certainly true under $0<\gamma<1-\beta$, since $\partial \ln (1-\beta-\gamma) / \partial \gamma<0$. 
- Proposition 3. First, consider that the first-order necessary condition for the choice of utilization with the tax and subsidy solves for the firm-level utilization as

$$
u=\left(\frac{1-\omega}{1-s}\right)^{\frac{\beta}{1-\beta}} \tilde{u}^{\frac{\gamma}{1-\beta}}
$$

Imposing the equilibrium condition $u=\tilde{u}$, we find

$$
u^{s u b s}=\left(\frac{1-\omega}{1-s}\right)^{\frac{\beta}{1-\beta-\gamma}}
$$

The comparison with equation (11) makes it clear that $s=\gamma$ achieves the socially-coordinated utilization rate.

To prove the second claim, differentiate equations (26) and (25) (after taking logs for simplicity) with respect to the subsidy $s$ to see that

$$
\frac{\partial \ln u^{\text {subs }}}{\partial s}=\frac{\beta}{1-\beta-\gamma} \frac{1}{1-s}>\frac{\partial \ln u}{\partial s}=\frac{\beta}{1-\beta} \frac{1}{1-s} \Longleftrightarrow \gamma \in(0,1-\beta) .
$$

The size of the fiscal multiplier $m$ can be recovered by dividing the aggregate response by the individual response. We have that

$$
m=\frac{1-\beta}{1-\beta-\gamma}=\frac{1}{1-\frac{\gamma}{1-\beta}}
$$

\section{References}

Auerbach, P., and Skott, P., 1988. 'Concentration, Competition, and Distribution - A Critique of the Theories of Monopoly Capital.' International Review of Applied Economics 2(1): 42-61.

Cooper, R., 1999. Coordination Games. Cambridge, UK: Cambridge University Press.

Drandakis, E.M. and Phelps, E.S. (1965) A model of induced invention, growth and distribution. Economic Journal 76(304): 82317840.

Duménil, G., and Levy, D., 1999. 'Being Keynesian in the Short Term and Classical in the Long Term: the Traverse to Classical Long-Term Equilibrium.' Manchester Shool 67(6): 684-716. 
Foley, D. K., Michl, T. R., and Tavani, D., 2019. Growth and Distribution, Second Edition Cambridge, MA: Harvard University Press.

Foley, D. K., 2003. 'Endogenous Technical Change with Externalities in a Classical Growth Model'. Journal of Economic Behavior and Organization...

Foley, D. K., 2016. 'Keynes' Microeconomics of Output and Labor Markets.' In Bernard, L., and Nyambuu, eds. Dynamic Modeling, Empirical Macroeconomics, and Finance: Essays in Honor of Willi Semmler, Springer, pp. 183-194.

Funk, P., 2002. Induced innovation revisited. Economica 69: 15517171.

Goodwin, R., 1967. 'A Growth Cycle'. In: Socialism, capitalism, and economic growth. Cambridge, UK: Cambridge University Press.

Greenwod, J., Hercowitz, Z., and Huffman, G., 1988. 'Investment, Capacity utilization, and the Real Business Cycle.' American Economic Review 78(3): 402-417.

Julius, A. J., 2005. Steady State Growth and Distribution with an Endogenous Direction of Technical Change. Metroeconomica...

Kaldor, N., 1956. 'Alternative theories of distribution.' Review of Economic Studies 23(2): 83-100.

Kaldor, N., 1961. 'Capital accumulation and economic growth.' In F. A. Lutz and D. C. Hague (eds.) The Theory of Capital. New York, NY: St. Martins Press.

Kennedy, C. (1964) Induced bias in innovation and the theory of distribution. Economic Journal 74(295): 54117547.

Keynes, J. M., 1936. The General Theory of Employment, Interest and Money. London: MacMillan.

Michl, T. R., 2009. Capitalists, Workers, and Fiscal Policy. Cambridge, MA: Harvard University Press.

Michl, T. R., 2017. "Profit-led Growth and the Stock Market." Review of Keynesian Economics, 5(1): 61-77. 
Michl, T. R., and Oliver, K. M. 2019. "Combating Hysteresis with Output Targeting." Review of Keynesian Economics, 7(1): 6-27.

van der Ploeg, R., 1985. Classical Growth Cycles. Metroeconomica 37(2): 221-230.

Setterfield, M. 2018. "Long-run Variation in Capacity Utilization in the Presence of a Fixed Normal Rate." Cambridge Journal of Economics, bey016.

Shah, and Desai, M., 1981.

Skott, P., 1989. Conflict and Effective Demand in Economic Growth. Cambridge, UK: Cambridge University Press.

Skott, P. 2010. 'Growth, Instability and Cycles: Harrodian and Kaleckian Models of Accumulation and Income Distribution.' In M. Setterfield, Ed., Handbook of Alternative Theories of Economic Growth. London, UK: Edward Elgar.

Skott, P., 2012. 'Theoretical and Empirical Shortcomings of the Kaleckian Investment Function.' Metroeconomica 63(1): 109-138.

Skott, P. 2017. "Weaknesses of Wage-led Growth.” Review of Keynesian Economics, 5(3): 336-359.

Tavani, D., and Petach, L., 2018. 'No one is Alone: Strategic Complementarities, Capacity Utilization, Growth, and Income Distribution' (April 8, 2018) Available at SSRN: https://ssrn.com/abstract=3123149.

Tavani, D.,and Zamparelli, L., 2015. 'Endogenous Technical Change, Employment and Distribution in the Goodwin Model of the Growth Cycle'. Studies in Nonlinear Dynamics and Econometrics 19(2): 209-226.

Tavani, D., and Zamparelli, L., 2017. 'Growth, Income Distribution, and the Entrepreneurial State.' Journal of Evolutionary Economics 2018. https://doi.org/10.1007/s00191-018-0555-7. 